\title{
Triptans and CGRP blockade - impact on the cranial vasculature
}

\author{
Silvia Benemei ${ }^{i^{* \dagger}} \mathbb{B}$, Francesca Cortese ${ }^{2 \dagger}$, Alejandro Labastida-Ramírez ${ }^{3 \dagger}$, Francesca Marchese ${ }^{4 \dagger}$, Lanfranco Pellesi ${ }^{5 \dagger}$, \\ Michele Romoli ${ }^{6+}$, Anne Luise Vollesen ${ }^{7 \dagger}$, Christian Lampl ${ }^{8+}$, Messoud Ashina ${ }^{9 \dagger}$ and On behalf of the School of \\ Advanced Studies of the European Headache Federation (EHF-SAS)
}

\begin{abstract}
The trigeminovascular system plays a key role in the pathophysiology of migraine. The activation of the trigeminovascular system causes release of various neurotransmitters and neuropeptides, including serotonin and calcitonin gene-related peptide (CGRP), which modulate pain transmission and vascular tone. Thirty years after discovery of agonists for serotonin $5-\mathrm{HT}_{1 \mathrm{~B}}$ and 5-HT ${ }_{1 \mathrm{D}}$ receptors (triptans) and less than fifteen after the proof of concept of the gepant class of CGRP receptor antagonists, we are still a long way from understanding their precise site and mode of action in migraine. The effect on cranial vasculature is relevant, because all specific anti-migraine drugs and migraine pharmacological triggers may act in perivascular space. This review reports the effects of triptans and CGRP blocking molecules on cranial vasculature in humans, focusing on their specific relevance to migraine treatment.
\end{abstract}

Keywords: Triptans, Calcitonin gene related peptide - CGRP, Anti-CGRP (receptor) monoclonal antibodies - mAbs, Middle meningeal artery, Middle cerebral arteries, Migraine models, Magnetic resonance angiography (MRA)

\section{Keypoints}

Triptans constrict extracerebral, but no intracerebral arteries, in healthy volunteers and migraine patients. The vasoconstrictor action of sumatriptan on extracerebral arteries could be relevant to relief migraine pain. However, sumatriptan also inhibits perivascular neurogenic inflammation and sensitization in animal models.

Gepants prevent CGRP-induced dilation of extracerebral arteries (e.g. middle meningeal and temporal arteries) in experimental human models.

Data on effect of anti-CGRP (receptor) monoclonal antibodies on cranial vasculature is still lacking. Importantly, preclinical models show their ability to inhibit CGRP-induced neurogenic vasodilation of the middle meningeal artery.

\section{Background}

Over the last century, controversies have raised around the vascular, neural or neurovascular origin of migraine [1]. From Galen original conjecture [2], with a meningeal

\footnotetext{
* Correspondence: silvia.benemei@unifi.it

${ }^{\dagger}$ Equal contributors

${ }^{1}$ Health Sciences Department, University of Florence, and Headache Centre,

Careggi University Hospital, Viale Pieraccini 6, 50134 Florence, Italy

Full list of author information is available at the end of the article
}

involvement in the throbbing pain, several centuries passed before Willis, in 1672, hinted for the first time at a "vascular hypothesis" of migraine [3]. Throughout the 1930 s and early 1940s headache science has emerged from studies by Graham, Ray and Wolff, who reported head pain after in vivo stimulation of dural and cerebral arteries, hypothesizing perivascular space as the possible site of migraine pain [4-7]. Pial, dural and extracranial vessels are part of a trigeminovascular system, a functional pathway that, on one side, releases vasoactive neuropeptides from perivascular nerve fibers and, on the other, reacts to them with nociception and vasodilation [8]. Pursuing the vascular hypothesis, several pharmacological triggers (such as glyceryl trinitrate (GTN), calcitonin gene-related peptide (CGRP) and pituitary adenylate cyclase-activating peptide (PACAP-38) were found to induce attacks phenotypically indistinguishable from spontaneous migraine in migraine patients [9-11]. The fact that all migraine-provoking molecules are vasoactive and sumatriptan constricts arteries [12, 13], further granted a key role of cranial vasculature in migraine pathophysiology [14].

Cranial arteries dilation has been shown, with different techniques, in both provocation and spontaneous 
migraine studies. Since the early 1990s, ultrasonography has been used to measure blood flow velocity in intracranial arteries [15] and extracranial artery diameter [16] during migraine attacks. Blood flow velocity correlates to vessel autoregulation and reactivity. Moreover, if cerebral blood flow does not change during an attack, blood flow velocity may be a surrogate marker of artery diameter (i.e. decreased blood flow velocity means increased middle cerebral artery lumen) [17]. In the last decade, investigation techniques have moved from ultrasonography to magnetic resonance angiography (MRA), allowing researchers to directly measure artery circumference [18-22]. MRA studies reported modest artery dilation during attacks, which was inhibited by triptans $[12,18$, $21,23]$. Similar results, with prevention of superficial temporal artery dilation, were reported with the CGRP receptor antagonist olcegepant [24], hence suggesting that the modulation of cranial vasculature tone or perivascular nociception is of paramount importance in migraine treatment, too.

Despite above mentioned evidence, the heated debate about the role of cranial vasculature in migraine pathophysiology is still open, and some authors have questioned whether cranial arteries play a significant role or only represent a negligible epiphenomenon $[25,26]$. Even though the precise site where migraine origins still remains elusive, consistent evidence suggests that initial mechanisms may dilate intra- and extra-cerebral arteries, and cranial vasoconstriction may mediate at least a part of the effects of antimigraine abortive drugs [8]. Thus, considering treatments on the verge of entering the clinical practice, such as CGRP blocking molecules, cranial arteries are undoubtedly of major interest in migraine.

This review reports the effects of triptans and CGRP (receptor) blocking molecules on cranial vasculature in humans, focusing on their specific relevance to migraine treatment. The classification of cranial vessels as intracranial - intracerebral and extracerebral - and extracranial, is shown in Table 1.

Table 1 Intracranial intracerebral and extracerebral and extracranial vessels

Cranial vessels may be extracranial and intracranial, and these latter may be distinguished into intracerebral and extracerebral. The middle cerebral artery and the cerebral part of the internal carotid artery are intracerebral vessels, while the cavernous part of the internal carotid artery is extracerebral. On the other hand, according to current imaging detection limitations, both the middle meningeal artery and the superficial temporal artery are considered extracranial vessels. Importantly, the middle meningeal artery has an intracranial and heavily innervated portion that may even be of more relevance in the pathophysiology of migraine than the extracranial portion. However, throughout the text and in accordance with current evidence that are about the extracranial portion, the text refers to middle meningeal artery as to an extracranial vessel.

\section{Triptans}

The development and consequent introduction of triptans represented an unprecedented revolution in migraine history, being the first successful attempt of rational and mechanism-driven treatment of migraine attacks. Compared to ergot alkaloids (ergotamine, dihydroergotamine and methysergide), that are non-specific serotonin type $1\left(5-\mathrm{HT}_{1}\right)$ receptor agonists as they target also 5-HT2, adrenergic and dopaminergic receptors, triptans act as selective agonists at $5-\mathrm{HT}_{1 \mathrm{~B}}$ and $5-\mathrm{HT}_{1 \mathrm{D}}$ subtypes, displaying a more favourable risk profile to ergots [27, 28].

The rationale for triptans development has been based on the vascular theory of migraine, together with the hypothesis that serotonin and serotonin receptors are involved in migraine pathophysiology. It has been shown that during a migraine attack high levels of hydroxyindoleacetic acid, a serotonin metabolite, are excreted [29] and that monoamine depletors induce migraine attacks that are aborted by intravenous infusion of serotonin [30]. To develop selective cranial vasoconstrictors and to avoid risky side effects of ergot alkaloids (i.e. a marked and long-lasting vasoconstriction in peripheral vessels), Humphrey and colleagues identified the 5-HT1-like receptor, later discovered to consist of both the 5 -HT1B and the 5-HT1D receptor subtypes, mostly located in cranial vessels, and then developed the first triptan, known as sumatriptan (GR43175) [31, 32]. Because of its efficacy and safety (including cardiovascular safety), sumatriptan has become a landmark in the treatment of migraine attacks [33]. Nevertheless, some peculiarities, such as the low oral bioavailability and short half-life [34], have favoured the development of new molecules, the so-called "second-generation" triptans (almotriptan, eletriptan, frovatriptan, naratriptan, rizatriptan), with an optimization of the pharmacokinetic profile [35].

Triptans are $5-\mathrm{HT}_{1 \mathrm{~B} / 1 \mathrm{D}}$ receptor agonists, most of them showing a moderate to high affinity for $5-\mathrm{HT}_{1 \mathrm{~F}}$ receptors as well [35]. Immunohistochemical studies have shown that $5-\mathrm{HT}_{1 \mathrm{~B}}$ receptors are mainly located within the smooth muscle and in the endothelium of human middle meningeal $[36,37]$ and cerebral $[38]$ arteries. Importantly, in in vitro studies, triptans constrict these arteries [37-39]. The 5- $\mathrm{HT}_{1 \mathrm{~B}}$ receptors, together with the $5-\mathrm{HT}_{1 \mathrm{D}}$ and $5-\mathrm{HT}_{1 \mathrm{~F}}$ receptors, are also located within the trigeminal nerve endings and trigeminal nucleus, suggesting that their stimulation could inhibit the release of proinflammatory neuropeptides (e.g. CGRP) and, consequently, the nociceptive transmission [40]. In a randomized placebo-controlled study, the administration of PNU142633, a selective 5- $\mathrm{HT}_{1 \mathrm{D}}$ receptor agonist, failed to alleviate the pain of acute migraine, suggesting a secondary role for $5-\mathrm{HT}_{1 \mathrm{D}}$ [41]. On the other side, selective nonvasoconstrictive $5-\mathrm{HT}_{1 \mathrm{~F}}$ receptor agonists, LY334370 [42] 
and LY573144 (i.e. lasmiditan) [43] demonstrated clinical efficacy, even though it remains to be confirmed whether these molecules, at therapeutic concentrations, are devoid of any activity on $5-\mathrm{HT}_{1 \mathrm{~B}}$ receptors. Interestingly, lasmiditan did not exer vasoactive effects in supratherapeutic concentrations [44]. Importantly, the high cranial (i.e. middle meningeal artery) $5-\mathrm{HT}_{1 \mathrm{~B}}$ receptor density compared to peripheral (i.e. coronary artery) blood vessels probably renders the triptans relatively selective for producing cranial vasoconstriction $[36,45]$.

Human experimental data about vessel responses to triptans (Fig. 1) have refined our comprehension of triptan antimigraine effects and, indirectly, of the migraine mechanism. Differently from what observed in vitro and in vivo [46], a placebo-controlled singlephoton emission computed tomography (SPECT) study on healthy volunteers showed that sumatriptan infusion did not modify total and regional cerebral perfusion [47]. Interestingly, contrasting data in migraine patients have been initially reported about the correspondence between sumatriptan-related blood velocity modifications, measured by Doppler sonography, and the resolution of migraine attacks [12, 48, 49]. Importantly, combining the measurement of the regional cerebral blood flow and the blood velocity in the middle cerebral arteries, sumatriptan infusion has been shown to reverse the abnormal dilation of the middle cerebral artery in the headache side [12]. This finding suggests that the sumatriptan-induced vasoconstriction occurs only in the dilated vessels, without affecting normal ones.

\section{Triptans and cranial vasculature}

A key feature of migraine is that attacks can be provoked by pharmacological triggers, including GTN [50] and, as detailed below, the provocation migraine models have provided important data on the role of cranial vasculature in migraine.

The efficacy of triptans in GTN-induced headache was investigated in healthy volunteers in double-blind, placebo-controlled, crossover studies. Sumatriptan (6 mg) administered subcutaneously $20 \mathrm{~min}$ before GTN $(0.12 \mu \mathrm{g} / \mathrm{kg} / \mathrm{min})$ infusion, relieved pain and decreased temporal artery diameter without affecting blood velocity of middle cerebral artery (MCA) [51]. On the other hand, zolmitriptan $(5 \mathrm{mg})$, administered orally during ongoing GTN infusion $(0.2 \mu \mathrm{g} / \mathrm{kg} / \mathrm{min})$ had no effects on the induced-headache [52]. Oral triptans (rizatriptan $10 \mathrm{mg}$, sumatriptan $50 \mathrm{mg}$ and zolmitriptan $2.5 \mathrm{mg}$ ) were also tested in migraine patients, in which they have been shown to both decrease diameter and increase resistance of temporal artery, although to a different extent [53]. More recently, the triptan effect was examined after the experimental administration of vasoactive neuropeptides such as CGRP, PACAP-38 and VIP, in healthy volunteers and migraine patients. In a first study, 18 healthy volunteers were randomized to receive an intravenous infusion of human $\alpha$-CGRP $(1.5 \mu \mathrm{g} / \mathrm{min})$ or placebo, for $20 \mathrm{~min}$ [18]. After $45 \mathrm{~min}$, a single dose of subcutaneous sumatriptan $(6 \mathrm{mg})$ was administered to each patient. A highresolution MRA was performed at baseline, before and after the sumatriptan injection, to measure the changes in the circumference of the MCA and middle meningeal

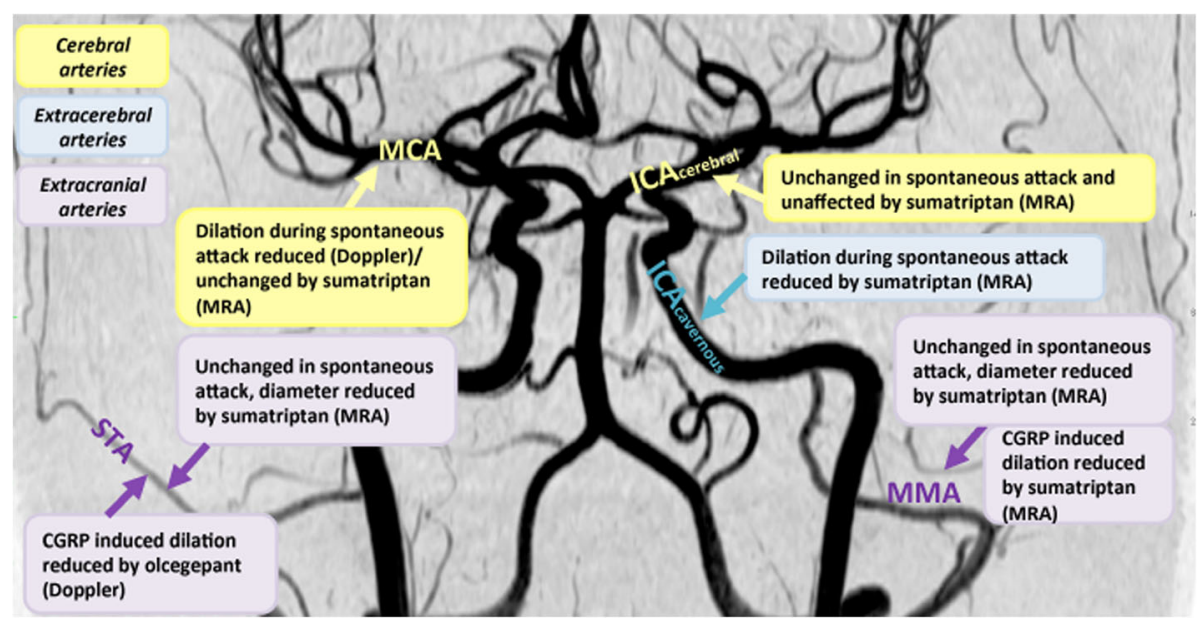

Fig. 1 Effects of sumatriptan and olcegepant on cranial vessels in migraine patients. The intracerebral vessels, the middle cerebral artery (MCA) and the cerebral part of the internal carotid artery (ICA $\left.\mathrm{A}_{\text {cerebral }}\right)$, are both shown in yellow. The extracerebral artery, the cavernous part of the internal carotid artery (ICA cavernous), is shown in blue. The extracranial vessels, the middle meningeal artery (MMA) and the superficial temporal artery (STA), are both shown in purple. Boxes include description of vessel reactivity during spontaneous and/or CGRP induced attacks as well as vessel response to sumatriptan and/or olcegepant. Imaging modality indicated in parentheses in boxes; magnetic resonance angiography (MRA) or transcranial ultrasound Doppler (Doppler). Image from MRA of healthy volunteer kindly provided by Faisal M Amin 
artery (MMA). Compared to placebo, CGRP caused significant dilation of MMA but not of MCA, and sumatriptan reduced the MMA circumference after CGRP pre-treatment by $25 \%$ and to a lesser extent on MCA, suggesting that sumatriptan exerts part of its antinociceptive effect primarily acting on MMA. A second study was performed in 24 patients with migraine without aura [23], in which the CGRP intravenous infusion always resulted in a delayed headache, which fulfilled the criteria for migrainelike attacks in 18 patients (75\%). MRA was performed in 15 of 18 patients, and of these, 10 (67\%) patients reported unilateral head pain. MMA and MCA were dilated only on the painful side. The other 5 patients (33\%) reported bilateral head pain, accompanied by a bilateral dilatation of both MMA and MCA. Sumatriptan subcutaneous injection reversed the dilatation of MMA and aborted the migraine attacks, without affecting MCA circumference [23]. These data show that migraine is associated with dilatation of extracerebral and intracerebral arteries, but only the contraction of extracerebral arteries is associated with amelioration of headache.

PACAP-38 is a vasoactive neuropeptide that belongs to the secretin/glucagon/VIP family and it is used to provoke experimental headache and migraine [10]. PACAP-38 is reported to cause delayed headache in healthy volunteers, associated with a significant and long-lasting dilatation of the MMA (up to 23\%), but no change in the MCA circumference [19]. In comparison, sumatriptan induced a contraction of the MMA by $12.3 \%$ and reversed the delayed headache attack, but no effects on the MCA were observed. The role of PACAP38 was further investigated in a double-blind crossover study [22] conducted in 22 female migraine patients without aura. Sixteen patients (73\%) after PACAP-38 infusion, but only four patients (18\%) after VIP infusion $(8 \mathrm{pmol} / \mathrm{kg} / \mathrm{min})$, reported migraine-like attacks. Both peptides induced a marked dilatation of the extracranial arteries, but not of the intracranial arteries. The subcutaneous injection of sumatriptan reversed migraine attacks simultaneously to the constriction of the dilated extracerebral arteries, but not the intracerebral arteries.

To date, only one MRA study has explicitly investigated cranial arteries during spontaneous migraine attacks [20]. Migraine attacks, with a median time from pain onset to scan of $5 \mathrm{~h} 45 \mathrm{~min}$, are not accompanied by extracranial arterial dilation on the pain side, but only by slight dilation of intracerebral arteries, MCA and internal carotid (ICA). In addition, the dilatation of the intracerebral arteries persisted after subcutaneous injection of sumatriptan, which however relieved migraine pain and reduced the circumference of notdilated extracranial arteries. These data suggested that the vasoconstrictor action of sumatriptan evident in extracranial arteries and in the cavernous portion of the ICA could be relevant to relief migraine. However, these findings do not refuse possible nociceptive input from other extracranial structures, in the absence of dilatation, such as CGRP-releasing sensitized perivascular afferents. Interestingly, recent data in humans suggested that the decrease of capsaicininduced dermal blood flow may be mediated by the inhibition of CGRP release [54].

\section{CGRP and cranial vasculature}

CGRP is a potent vasodilator expressed and released in the perivascular space by trigeminal sensory neurons with a central role in neurogenic inflammation [55]. CGRP receptor consists of three components: calcitonin-receptor-like receptor (CLR), receptor component protein (RCP) and a specific chaperone called receptor activity modifying protein 1 (RAMP1) [56]. Importantly, CLR and RAMP1 expression has been shown in human middle meningeal [57], middle cerebral, pial and superficial temporal arteries [58], demonstrating the presence of all essential components required for a functional CGRP receptor in these districts.

Several small molecule antagonists targeting the CGRP receptor have been developed [59] for the treatment of acute migraine attack and have shown efficacy in clinical trials. Olcegepant (BIBN4096BS) was the first selective and hydrophilic non-peptide CGRP receptor antagonist with an extremely high affinity and specificity for the human CGRP receptor [60] showing clinical efficacy in migraine attacks [61]. In comparison to triptans, which have been extensively studied in humans, most data on vascular effects of "gepants" come from preclinical studies and this has been previously reviewed [62]. Olcegepant, which inhibits dose-dependent relaxation of isolated human cerebral arteries [63], blocks MMA vasodilation following systemic administration of $\alpha$-CGRP and $\beta$-CGRP, without significantly affecting pial artery dilation or the local cortical cerebral blood flow increase [64]. In contrast to the pial vessels, the meningeal arteries have no blood-brain barrier [65], suggesting that olcegepant likely acts outside of the blood-brain barrier [66]. In humans, olcegepant per se had no constrictor effect on the middle cerebral, radial, and superficial temporal artery [24], and no influence on global and regional cerebral blood flow [67]. Nevertheless, olcegepant effectively antagonizes the extracerebral vascular effect (e.g. temporal artery dilation) induced by CGRP intravascular administration [24]. A series of orally bioavailable small molecule CGRP receptor antagonists, including MK-0974 (telcagepant), have been then developed giving rise to the pharmacological class of "gepants". Telcagepant has been shown to be able to abort CGRP-induced vasodilatation on human cerebral and meningeal arteries ex vivo [68]. However, notwithstanding efficacy in clinical trials [69], clinical development 
of early gepants has been discontinued [70], and accordingly their use in migraine models has been withdrawn.

There are currently four monoclonal antibodies (mAb) in clinical development for migraine prophylaxis: three humanized mAb targeting CGRP (LY2951742/galcanezumab, Eli Lilly and Company; ALD403/eptinezumab, Alder Biopharmaceuticals; and TEV-48215/fremanezumab, TEVA Pharmaceuticals) and one fully human mAb targeting the CGRP receptor (AMG 334/erenumab, Amgen). These biological drugs have shown efficacy, tolerability and few adverse effects in phase 2 randomized control trials [71-76]. However, their exact site and mechanism of action is not completely understood. The new CGRP mAbs are macromolecules (around $150,000 \mathrm{Da})$ that are unlikely to cross the blood-brain barrier [66]. In line with this, few preclinical studies revealed that humanized CGRP $\mathrm{mAb}$ are (i) unable to penetrate the blood-brain barrier in the perfused MCA [77]; (ii) ineffective in inhibiting the responses to CGRPinduced neurogenic vasodilation of the pial artery [78]; and (iii) capable of inhibiting CGRP-induced neurogenic vasodilation of the MMA, which as mentioned above lacks blood-brain barrier [65, 79]. Importantly, it has been recently shown that there is no blood-brain barrier disruption during migraine attacks [80]. All these findings taken into account suggest a peripheral vascular site of action of the mAbs.

A similar alternative under development for the preventive treatment of migraine is blocking CGRP-induced receptor activation through a RNA-Spiegelmer (NOXC89). This single-strand mirror-image oligonucleotide binds to circulating CGRP and is highly resistant to endogenous nuclease degradation, hence inhibiting its function. Interestingly, this drug could not inhibit neurogenic vasodilation of pial arteries in vivo, which suggested that it is unlikely to penetrate the blood-brain barrier readily [78].

Targeting peripheral CGRP may reduce or prevent the phenomenon (i.e. vasodilation) that has been advocated as a mechanism of headache and associated symptoms, whereas whether long-term inhibition of CGRP outside of the blood-brain barrier induces modulation of central pathways remains unknown. Further studies are needed to fully clarify the exact antimigraine site of action of the CGRP mAbs and NOX-C89.

\section{Conclusions}

From Galen's quote about meninges and vessels as mediators, together with other structures and mechanisms of migraine pain, long time has passed. In the last years, notwithstanding many detractors, cranial vasculature involvement in the pathogenesis of migraine pain has benefited from experimental data acquired by modern imaging techniques, such as MRA, and specific pharmacological tools, such as triptans. Recently developed human migraine models have suggested that attention should be paid to cranial extracerebral arteries (i.e. MMA) in addition to intracerebral vessels, which were the major focus at the dawn of vascular migraine research. On the basis of current knowledge [20, 23], future studies should investigate whether there are differences in how the perivascular nerves innervate the different sections of the MMA, including dural branches, because it is likely that it is activation or inhibition of the perivascular nerves that is associated with migraine pain relief. In addition, future advanced brain imaging methods will allow to investigate possible dilatation of dural branches of the MMA that are very difficult to visualise with current method, without injection of contrast agents [20]. The availability of innovative migraine-specific drugs, such as CGRP-targeted compounds [69], will further increase our ability to investigate the involvement of cranial vasculature in migraine pain, and will finally allow to properly balance the weight of vessel contribution to the neurovascular theory of migraine.

\section{Abbreviations}

5-HT: serotonin (5-hydroxytriptamine); CGRP: calcitonin gene-related peptide; CLR: calcitonin-receptor-like receptor; GTN: glyceryl trinitrate; ICA: internal carotid artery; MCA: middle cerebral artery; MMA: middle meningeal artery; MRA: magnetic resonance angiography; PACAP-38: pituitary adenylate cyclaseactivating peptide; RAMP1: receptor activity modifying protein 1; RCP: receptor component protein; SPECT: single-photon emission computed tomography; STA: superficial temporal artery; VIP: vasoactive intestinal peptide.

\section{Acknowledgments}

This work was supported by the Department of Clinical and Molecular Medicine, Sapienza University, Rome, and the School of Advanced Studies of the European Headache Federation (EHF-SAS).

\section{Authors' contributions}

All Authors equally contributed to the review. SB, FC, ALR, FM, LP, MR, LV are Junior Fellows of EHF-SAS. CL and MA are Senior Fellows of EHF-SAS. All authors read and approved the final manuscript.

\section{Competing interests}

Prof Messoud Ashina is a consultant or scientific advisor for Allergan, Amgen, Alder, ATI and Eli Lilly, primary investigator for Amgen 20,120,178 (Phase 2), 20,120,295 (Phase 2), 20,130,255 (OLE), 20,120,297 (Phase 3) and GM-11 gammaCore-R trials, and reports grants from Lundbeck Foundation (R155-2014-171), Research Foundation of the Capital Region of Copenhagen, Danish Council for Independent Research, Medical Sciences and Novo Nordisk Foundation (NNF110C101433). Other authors have no competing interests.

\section{Publisher's Note}

Springer Nature remains neutral with regard to jurisdictional claims in published maps and institutional affiliations.

\section{Author details}

${ }^{1}$ Health Sciences Department, University of Florence, and Headache Centre, Careggi University Hospital, Viale Pieraccini 6, 50134 Florence, Italy. ${ }^{2}$ Department of Medico-Surgical Sciences and Biotechnologies, Sapienza University of Rome, Polo Pontino, Latina, Italy. ${ }^{3}$ Dept Internal Medicine, Division of Vascular Pharmacology, Erasmus Medical Center, Rotterdam, The Netherlands. ${ }^{4}$ Child Neuropsichiatry Unit, University of Palermo, Palermo, Italy. ${ }^{5}$ Medical Toxicology Headache and Drug Abuse Center, University of Modena and Reggio Emilia, Modena, Italy. ${ }^{6}$ Neurology Clinic, University 
Hospital of Perugia, Perugia, Italy. ${ }^{7}$ Danish Headache Center and Department of Neurology, Rigshospitalet Glostrup, Faculty of Health and Medicl Sciences, University of Copenhagen, Copenhagen, Denmark. ${ }^{8}$ Department of Neurogeriatric Medicine, Headache Medical Center Linz, Linz, Austria. ${ }^{9}$ Danish Headache Center and Department of Neurology, Rigshospitalet Glostrup, Faculty of Health and Medical Sciences, University of Copenhagen, Copenhagen, Denmark.

\section{Received: 2 August 2017 Accepted: 25 September 2017 Published online: 10 October 2017}

\section{References}

1. Messlinger K (2009) Migraine: where and how does the pain originate? Exp Brain Res 196:179-193

2. Isler H (1992) The Galenic tradition and migraine. J Hist Neurosci 1:227-233

3. Willis $T$ (1672) Two Discourses concerning the soul of brutes (De anima brutorum). Part 1

4. Graham JR, Wolff HG (1938) Mechanism of migraine headache and action of ergotamine tartrate. Arch Neurol Psychiatr 39:737-763

5. Wolff HG (1938) Headache and cranial arteries. Trans Assoc Am Phys 53: 193-198

6. Ray BS, Wolff HG (1940) Experimental studies on headache: Pain-sensitive structures of the head and their significance in headache. Arch Surg 41: 813-856

7. Wolff HG, Tunis MM, Goodell H (1953) Studies on headache: evidence of tissue damage and changes in pain sensitivity in subjects with vascular headaches of the migraine type. Trans Assoc Am Phys 66:332-341

8. Olesen J, Burstein R, Ashina M, Ashina M, Tfelt-Hansen P, Tfelt-Hansen P (2009) Origin of pain in migraine: evidence for peripheral sensitisation. Lancet Neurol 8:679-690

9. Thomsen LL, Kruuse C, Iversen HK, Olesen J (1994) A nitric oxide donor (nitroglycerin) triggers genuine migraine attacks. Eur J Neurol 1:73-80

10. Schytz HW, Birk S, Wienecke T, Kruuse C, Olesen J, Ashina M (2009) PACAP38 induces migraine-like attacks in patients with migraine without aura. Brain 132:16-25

11. Hansen JM, Hauge AW, Olesen J, Ashina M (2010) Calcitonin gene-related peptide triggers migraine-like attacks in patients with migraine with aura. Cephalalgia 30:1179-1186

12. Thomaides T, Karagounakis D, Spantideas A, Katelanis S (2003) Transcranial Doppler in migraine attacks before and after treatment with oral zolmitriptan or sumatriptan. Headache 43:54-58

13. Chan KY, Vermeersch $S$, de Hoon J, Villalon CM, Maassenvandenbrink A (2011) Potential mechanisms of prospective antimigraine drugs: a focus on vascular (side) effects. Pharmacol Ther 129:332-351

14. Thomsen LL, Iversen HK, Olesen J (1995) Cerebral blood flow velocities are reduced during attacks of unilateral migraine without aura. Cephalalgia 15 $109-116$

15. Iversen HK, Nielsen TH, Olesen J, Tfelt-Hansen P (1990) Arterial responses during migraine headache. Lancet 336:837-839

16. Markwalder TM, Grolimund P, Seiler RW, Roth F, Aaslid R (1984) Dependency of blood flow velocity in the middle cerebral artery on end-tidal carbon dioxide partial pressure-a transcranial ultrasound Doppler study. J Cereb Blood Flow Metab 4:368-372

17. Asghar MS, Hansen AE, Kapijimpanga T, van der Geest RJ, van der Koning P, Larsson HB, Olesen J, Ashina M (2010) Dilation by CGRP of middle meningeal artery and reversal by sumatriptan in normal volunteers. Neurology 75:1520-1526

18. Amin FM, Asghar MS, Guo S, Hougaard A, Hansen AE, Schytz HW, van der Geest RJ, de Koning PJ, Larsson HB, Olesen J, Ashina M (2012) Headache and prolonged dilatation of the middle meningeal artery by PACAP38 in healthy volunteers. Cephalalgia 32:140-149

19. Amin FM, Asghar MS, Hougaard A, Hansen AE, Larsen VA, de Koning PJ, Larsson HB, Olesen J, Ashina M (2013) Magnetic resonance angiography of intracranial and extracranial arteries in patients with spontaneous migraine without aura: a cross-sectional study. Lancet Neurol 12:454-461

20. Amin FM, Asghar MS, Ravneberg JW, de Koning PJ, Larsson HB, Olesen J, Ashina M (2013) The effect of sumatriptan on cephalic arteries: A 3T MRangiography study in healthy volunteers. Cephalalgia 33:1009-1016

21. Amin FM, Hougaard A, Schytz HW, Asghar MS, Lundholm E, Parvaiz Al, de Koning PJ, Andersen MR, Larsson HB, Fahrenkrug J, Olesen J, Ashina M (2014) Investigation of the pathophysiological mechanisms of migraine attacks induced by pituitary adenylate cyclase-activating polypeptide-38. Brain 137:779-794

22. Asghar MS, Hansen AE, Amin FM, van der Geest RJ, Koning P, Larsson HB, Olesen J, Ashina M (2011) Evidence for a vascular factor in migraine. Ann Neurol 69:635-645

23. Petersen KA, Lassen LH, Birk S, Lesko L, Olesen J (2005) BIBN4096BS antagonizes human alpha-calcitonin gene related peptide-induced headache and extracerebral artery dilatation. Clin Pharmacol Ther 77:202-213

24. Goadsby PJ, Holland PR, Martins-Oliveira M, Hoffmann J, Schankin C, Akerman S (2017) Pathophysiology of Migraine: A Disorder of Sensory Processing. Physiol Rev 97:553-622

25. Diener HC, Jansen JP, Reches A, Pascual J, Pitei D, Steiner TJ (2002) Efficacy, tolerability and safety of oral eletriptan and ergotamine plus caffeine (Cafergot) in the acute treatment of migraine: a multicentre, randomised, double-blind, placebo-controlled comparison. Eur Neurol 47:99-107

26. Sicuteri F, Testi A, Anselmi B (1961) Biochemical Investigations in Headache: Increase in the Hydroxyindoleacetic Acid Excretion During Migraine Attacks. Int Arch Allergy 19:55-58

27. Kimball RW, Friedman AP, Vallejo E (1960) Effect of serotonin in migraine patients. Neurology 10:107-111

28. Humphrey PP, Feniuk W, Perren MJ, Connor HE, Oxford AW (1989) The pharmacology of the novel 5-HT1-like receptor agonist, GR43175. Cephalalgia 9(Suppl 9):23-33

29. Doenicke A, Brand J, Perrin VL (1988) Possible benefit of GR43175, a novel 5-HT1-like receptor agonist, for the acute treatment of severe migraine. Lancet 1:1309-1311

30. Humphrey PP (2008) The discovery and development of the triptans, a major therapeutic breakthrough. Headache 48:685-687

31. Fowler PA, Lacey LF, Thomas M, Keene ON, Tanner RJ, Baber NS (1991) The clinical pharmacology, pharmacokinetics and metabolism of sumatriptan. Eur Neurol 31:291-294

32. Tfelt-Hansen P, De Vries P, Saxena PR (2000) Triptans in migraine: a comparative review of pharmacology, pharmacokinetics and efficacy. Drugs 60:1259-1287

33. Razzaque Z, Pickard JD, Ma OP, Shaw D, Morrison K, Wang T, Longmore J (2002) 5-HT1B-receptors and vascular reactivity in human isolated blood vessels: assessment of the potential craniovascular selectivity of sumatriptan. Br J Clin Pharmacol 53:266-274

34. Nilsson T, Longmore J, Shaw D, Olesen IJ, Edvinsson L (1999) Contractile 5-HT1B receptors in human cerebral arteries: pharmacological characterization and localization with immunocytochemistry. Br J Pharmacol 128:1133-1140

35. van den Broek RW, Bhalla P, VanDenBrink AM, de Vries R, Sharma HS, Saxena PR (2002) Characterization of sumatriptan-induced contractions in human isolated blood vessels using selective 5-HT(1B) and 5-HT(1D) receptor antagonists and in situ hybridization. Cephalalgia 22:83-93

36. Buzzi MG, Carter WB, Shimizu T, Heath H 3rd, Moskowitz MA (1991) Dihydroergotamine and sumatriptan attenuate levels of CGRP in plasma in rat superior sagittal sinus during electrical stimulation of the trigeminal ganglion. Neuropharmacology 30:1193-1200

37. Gomez-Mancilla B, Cutler NR, Leibowitz MT, Spierings EL, Klapper JA, Diamond S, Goldstein J, Smith T, Couch JR, Fleishaker J, Azie N, Blunt DE (2001) Safety and efficacy of PNU-142633, a selective 5-HT1D agonist, in patients with acute migraine. Cephalalgia 21:727-732

38. Goldstein DJ, Roon Kl, Offen WW, Ramadan NM, Phebus LA, Johnson KW, Schaus JM, Ferrari MD (2001) Selective serotonin 1F (5-HT(1F)) receptor agonist LY334370 for acute migraine: a randomised controlled trial. Lancet 358:1230-1234

39. Ferrari MD, Farkkila M, Reuter U, Pilgrim A, Davis C, Krauss M, Diener HC (2010) Acute treatment of migraine with the selective 5-HT1F receptor agonist lasmiditan-a randomised proof-of-concept trial. Cephalalgia 30:1170-1178

40. Rubio Beltran E, Kristian H, Labastida A, de Vries R, Danser J, Michael G, Peter S, Kovalchin J, Villalon C, MaassenVanDenBrink A (2016) Lasmiditan and sumatriptan: comparison of in vivo vascular constriction in the dog and in vitro contraction of human arteries. Cephalalgia 36(IS):104-105

41. MaassenVanDenBrink A, van den Broek RW, de Vries R, Bogers AJ, Avezaat CJ, Saxena PR (2000) Craniovascular selectivity of eletriptan and sumatriptan in human isolated blood vessels. Neurology 55:1524-1530

42. Feniuk W, Humphrey PP, Perren MJ (1989) The selective carotid arteria vasoconstrictor action of GR43175 in anaesthetized dogs. Br J Pharmacol 96:83-90

43. Scott AK, Grimes S, Ng K, Critchley M, Breckenridge AM, Thomson C, Pilgrim AJ (1992) Sumatriptan and cerebral perfusion in healthy volunteers. Br J Clin Pharmacol 33:401-404 
44. Friberg L, Olesen J, Iversen HK, Sperling B (1991) Migraine pain associated with middle cerebral artery dilatation: reversal by sumatriptan. Lancet 338:13-17

45. Ashina M, Hansen JM, Olesen J (2013) Pearls and pitfalls in human pharmacological models of migraine: 30 years' experience. Cephalalgia 33:540-553

46. Iversen HK, Olesen J (1996) Headache induced by a nitric oxide donor (nitroglycerin) responds to sumatriptan. A human model for development of migraine drugs. Cephalalgia 16:412-418

47. Tvedskov JF, Iversen HK, Olesen J, Tfelt-Hansen P (2010) Nitroglycerin provocation in normal subjects is not a useful human migraine model? Cephalalgia 30:928-932

48. de Hoon JN, Willigers JM, Troost J, Struijker-Boudier HA, Van Bortel LM (2000) Vascular effects of 5-HT1B/1D-receptor agonists in patients with migraine headaches. Clin Pharmacol Ther 68:418-426

49. Ibrahimi K, Danser A, Terwindt GM, van den Meiracker AH, MaassenVanDenBrink A (2017) A human trigeminovascular biomarker for antimigraine drugs: A randomised, double-blind, placebo-controlled, crossover trial with sumatriptan. Cephalalgia 37:94-98

50. Durham PL (2006) Calcitonin gene-related peptide (CGRP) and migraine. Headache 46(Suppl 1):S3-S8

51. Hay DL, Walker CS (2017) CGRP and its receptors. Headache 57:625-636

52. Gupta S, Mehrotra S, Avezaat CJ, Villalon CM, Saxena PR, Maassenvandenbrink A (2006) Characterisation of CGRP receptors in the human isolated middle meningeal artery. Life Sci 79:265-271

53. Oliver KR, Wainwright A, Edvinsson L, Pickard JD, Hill RG (2002) Immunohistochemical localization of calcitonin receptor-like receptor and receptor activity-modifying proteins in the human cerebral vasculature. $J$ Cereb Blood Flow Metab 22:620-629

54. Moore EL, Salvatore CA (2012) Targeting a family B GPCR/RAMP receptor complex: CGRP receptor antagonists and migraine. $\mathrm{Br} J$ Pharmacol 166:66-78

55. Doods H, Hallermayer G, Wu D, Entzeroth M, Rudolf K, Engel W, Eberlein W (2000) Pharmacological profile of BIBN4096BS, the first selective small molecule CGRP antagonist. Br J Pharmacol 129:420-423

56. Olesen J, Diener HC, Husstedt IW, Goadsby PJ, Hall D, Meier U, Pollentier S, Lesko LM (2004) Calcitonin gene-related peptide receptor antagonist BIBN 4096 BS for the acute treatment of migraine. N Engl J Med 350:1104-1110

57. Villalón CM, Olesen J (2009) The role of CGRP in the pathophysiology of migraine and efficacy of CGRP receptor antagonists as acute antimigraine drugs. Pharmacol Ther 124:309-323

58. Edvinsson L, Alm R, Shaw D, Rutledge RZ, Koblan KS, Longmore J, Kane SA (2002) Effect of the CGRP receptor antagonist BIBN4096BS in human cerebral, coronary and omental arteries and in SK-N-MC cells. Eur J Pharmacol 434:49-53

59. Petersen KA, Birk S, Doods H, Edvinsson L, Olesen J (2004) Inhibitory effect of BIBN4096BS on cephalic vasodilatation induced by CGRP or transcranial electrical stimulation in the rat. Br J Pharmacol 143:697-704

60. Edvinsson L (2008) CGRP blockers in migraine therapy: where do they act? Br J Pharmacol 155:967-969

61. Edvinsson L (2015) CGRP receptor antagonists and antibodies against CGRP and its receptor in migraine treatment. Br J Clin Pharmacol 80:193-199

62. Petersen KA, Birk S, Lassen LH, Kruuse C, Jonassen O, Lesko L, Olesen J (2005) The CGRP-antagonist, BIBN4096BS does not affect cerebral or systemic haemodynamics in healthy volunteers. Cephalalgia 25:139-147

63. Edvinsson L, Chan KY, Eftekhari S, Nilsson E, de Vries R, Saveland H, Dirven CM, Danser AH, MaassenVanDenBrink A (2010) Effect of the calcitonin generelated peptide (CGRP) receptor antagonist telcagepant in human cranial arteries. Cephalalgia 30:1233-1240

64. Ho TW, Ferrari MD, Dodick DW, Galet V, Kost J, Fan X, Leibensperger H, Froman S, Assaid C, Lines C, Koppen H, Winner PK (2008) Efficacy and tolerability of MK-0974 (telcagepant), a new oral antagonist of calcitonin gene-related peptide receptor, compared with zolmitriptan for acute migraine: a randomised, placebo-controlled, parallel-treatment trial. Lancet 372:2115-2123

65. Schuster NM, Rapoport AM (2016) New strategies for the treatment and prevention of primary headache disorders. Nat Rev Neurol 12:635-650

66. Dodick DW, Goadsby PJ, Silberstein SD, Lipton RB, Olesen J, Ashina M, Wilks K, Kudrow D, Kroll R, Kohrman B, Bargar R, Hirman J, Smith J (2014) Safety and efficacy of ALD403, an antibody to calcitonin gene-related peptide, for the prevention of frequent episodic migraine: a randomised, double-blind placebo-controlled, exploratory phase 2 trial. Lancet Neurol 13:1100-1107

67. Dodick DW, Goadsby PJ, Spierings EL, Scherer JC, Sweeney SP, Grayzel DS (2014) Safety and efficacy of LY2951742, a monoclonal antibody to calcitonin gene-related peptide, for the prevention of migraine: a phase 2, randomised double-blind, placebo-controlled study. Lancet Neurol 13:885-892

68. Bigal ME, Dodick DW, Rapoport AM, Silberstein SD, Ma Y, Yang R, Loupe PS, Burstein R, Newman LC, Lipton RB (2015) Safety, tolerability, and efficacy of TEV-48125 for preventive treatment of high-frequency episodic migraine: a multicentre, randomised, double-blind, placebo-controlled, phase $2 b$ study. Lancet Neurol 14:1081-1090

69. Bigal ME, Edvinsson L, Rapoport AM, Lipton RB, Spierings EL, Diener HC, Burstein R, Loupe PS, Ma Y, Yang R, Silberstein SD (2015) Safety, tolerability, and efficacy of TEV-48125 for preventive treatment of chronic migraine: $a$ multicentre, randomised, double-blind, placebo-controlled, phase 2b study. Lancet Neurol 14:1091-1100

70. Sun H, Dodick DW, Silberstein S, Goadsby PJ, Reuter U, Ashina M, Saper J, Cady R, Chon Y, Dietrich J, Lenz R (2016) Safety and efficacy of AMG 334 for prevention of episodic migraine: a randomised, double-blind, placebocontrolled, phase 2 trial. Lancet Neurol 15:382-390

71. Tepper S, Ashina M, Reuter U, Brandes JL, Dolezil D, Silberstein S, Winner P, Leonardi D, Mikol D, Lenz R (2017) Safety and efficacy of erenumab for preventive treatment of chronic migraine: a randomised, double-blind, placebo-controlled phase 2 trial. Lancet Neurol 16:425-434

72. Edvinsson L, Nilsson $E$, Jansen-Olesen I (2007) Inhibitory effect of BIBN4096BS, CGRP(8-37), a CGRP antibody and an RNA-Spiegelmer on CGRP induced vasodilatation in the perfused and non-perfused rat middle cerebral artery. Br J Pharmacol 150:633-640

73. Juhl L, Edvinsson L, Olesen J, Jansen-Olesen I (2007) Effect of two novel CGRP-binding compounds in a closed cranial window rat model. Eur J Pharmacol 567:117-124

74. Hougaard A, Amin FM, Christensen CE, Younis S, Wolfram F, Cramer SP, Larsson HBW, Ashina M (2017) Increased brainstem perfusion, but no bloodbrain barrier disruption, during attacks of migraine with aura. Brain 140: $1633-1642$

75. Goadsby PJ (2009) The vascular theory of migraine-a great story wrecked by the facts. Brain 132:6-7

76. TheMultinationalOralSumatriptanandCafergotComparativeStudyGroup (1991) A randomized, double-blind comparison of sumatriptan and Cafergot in the acute treatment of migraine. The Multinational Oral Sumatriptan and Cafergot Comparative Study Group. Eur Neurol 31:314-322

77. Longmore J, Razzaque Z, Shaw D, Davenport AP, Maguire J, Pickard JD, Schofield WN, Hill RG (1998) Comparison of the vasoconstrictor effects of rizatriptan and sumatriptan in human isolated cranial arteries: immunohistological demonstration of the involvement of 5-HT1B-receptors. Br J Clin Pharmacol 46:577-582

78. Caekebeke JF, Ferrari MD, Zwetsloot CP, Jansen J, Saxena PR (1992) Antimigraine drug sumatriptan increases blood flow velocity in large cerebral arteries during migraine attacks. Neurology 42:1522-1526

79. Limmroth V, May A, Auerbach P, Wosnitza G, Eppe T, Diener HC (1996) Changes in cerebral blood flow velocity after treatment with sumatriptan or placebo and implications for the pathophysiology of migraine. J Neurol Sci 138:60-65

80. Zeller J, Poulsen KT, Sutton JE, Abdiche YN, Collier S, Chopra R, Garcia CA, Pons J, Rosenthal A, Shelton DL (2008) CGRP function-blocking antibodies inhibit neurogenic vasodilatation without affecting heart rate or arterial blood pressure in the rat. Br J Pharmacol 155:1093-1103

\section{Submit your manuscript to a SpringerOpen ${ }^{\circ}$ journal and benefit from:}

- Convenient online submission

- Rigorous peer review

- Open access: articles freely available online

- High visibility within the field

- Retaining the copyright to your article

Submit your next manuscript at $>$ springeropen.com 